This item was submitted to Loughborough's Research Repository by the author.

Items in Figshare are protected by copyright, with all rights reserved, unless otherwise indicated.

\title{
Kinematic and kinetic differences between military patients with patellar tendinopathy and asymptomatic controls during single leg squats
}

\section{PLEASE CITE THE PUBLISHED VERSION}

https://doi.org/10.1016/j.clinbiomech.2019.02.001

\section{PUBLISHER}

(C) Elsevier

VERSION

AM (Accepted Manuscript)

\section{PUBLISHER STATEMENT}

This paper was accepted for publication in the journal Clinical Biomechanics and the definitive published version is available at https://doi.org/10.1016/j.clinbiomech.2019.02.001

\section{LICENCE}

CC BY-NC-ND 4.0

\section{REPOSITORY RECORD}

Barker-Davies, Robert M., Andrew Roberts, James Watson, Polly Baker, Alexander N. Bennett, Daniel Fong, Patrick Wheeler, and Mark Lewis. 2019. "Kinematic and Kinetic Differences Between Military Patients with Patellar Tendinopathy and Asymptomatic Controls During Single Leg Squats". figshare. https://hdl.handle.net/2134/37240. 


\section{Accepted Manuscript}

Kinematic and kinetic differences between military patients with patellar tendinopathy and asymptomatic controls during single leg squats

Robert M. Barker-Davies, Andrew Roberts, James Watson, Polly Baker, Alexander N. Bennett, Daniel T.P. Fong, Patrick Wheeler, Mark P. Lewis

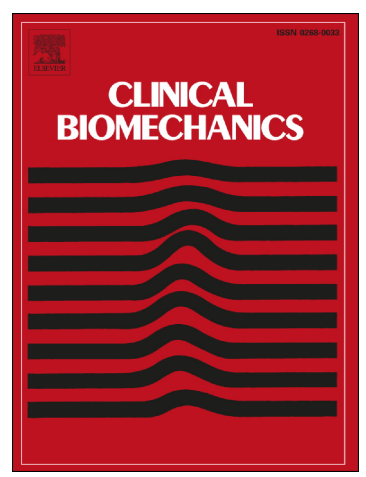

PII:

S0268-0033(18)30459-5

DOI: https://doi.org/10.1016/j.clinbiomech.2019.02.001

Reference: JCLB 4687

To appear in:

\section{Clinical Biomechanics}

Received date: $\quad 15$ December 2017

Accepted date: $\quad 1$ February 2019

Please cite this article as: R.M. Barker-Davies, A. Roberts, J. Watson, et al., Kinematic and kinetic differences between military patients with patellar tendinopathy and asymptomatic controls during single leg squats, Clinical Biomechanics, https:/doi.org/10.1016/ j.clinbiomech.2019.02.001

This is a PDF file of an unedited manuscript that has been accepted for publication. As a service to our customers we are providing this early version of the manuscript. The manuscript will undergo copyediting, typesetting, and review of the resulting proof before it is published in its final form. Please note that during the production process errors may be discovered which could affect the content, and all legal disclaimers that apply to the journal pertain. 


\section{Original Article}

\section{Kinematic and kinetic differences between military patients with patellar tendinopathy and asymptomatic controls during single leg squats}

Robert M Barker-Davies ${ }^{a, b \sharp}$, Andrew Roberts ${ }^{a, c}$, James Watson ${ }^{a}$, Polly Bakera Alexander N Bennett ${ }^{a, d}$, Daniel T P Fong ${ }^{b}$, Patrick Wheeler ${ }^{b}$, Mark P Lewis ${ }^{b}$

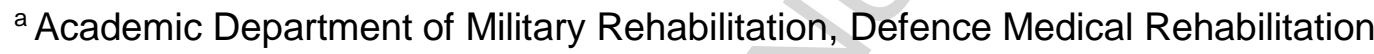
Centre Headley Court, London, UK

${ }^{b}$ National Centre for Sport and Exercise Medicine, School of Sport Exercise and Health Sciences, Loughborough University, UK

${ }^{c}$ Army Personnel Research Capability, Army Headquarters, Andover, UK

d National Heart and Lung Institute, Faculty of Medicine, Imperial College, London, UK

\#Corresponding Author R.Barker-Davies@lboro.ac.uk

Word count (excluding abstract, references, figures and tables): 3278

Abstract word count: 250

Tables: 5

Figures: 2

\section{Keywords}

Small Knee Bend, Kinematics, Kinetics, Military Personnel, Rehabilitation, Sports Medicine 
Abstract

Background. Knee valgus alignment has been associated with lower-limb musculoskeletal injury. This case-control study aims to: assess biomechanical differences between patients with patellar tendinopathy and healthy controls. Methods. 43 military participants (21 cases, 22 controls) were recorded using 3Dmotion capture performing progressively demanding, small knee bend, single leg and single leg decline squats. Planned a priori analysis of peak: hip adduction, knee flexion, pelvic tilt, pelvic obliquity and trunk flexion was conducted using MANOVA. Kinematic and kinetic data were graphed with bootstrapped t-tests and 95\% Cl's normalised to the squat cycle. ANOVA and correlations in SPSS were used for exploratory analysis.

Findings. Gases squatted to less depth $\left(-6.62^{\circ}, p<0.05\right)$, have greater abduction (valgus) angle with decreased abduction (valgus) moment, initiate and complete squatting with more trunk, hip and knee flexion associated with increased hip/knee extensor moment and hip/knee internal rotation moment $(p<0.05)$. On their symptomatic side cases squatted to less depth $\left(-6.62^{\circ}, \mathrm{p}<0.05\right)$ than controls with exploratory curve analysis revealing a pattern of increased knee valgus collapse throughout the squatting movement $(p<0.05)$. Greater patella tendon force was generated by: the eccentric than concentric phase of squatting $(+30-43 \%$, ES $0.52-$ 1.32, $\mathrm{p}<0.01)$, declined (plantarflexed) compared to horizontal surface $(+36-51 \%$, ES 1.19-1.68, $p<0.01)$ and deeper knee flexion angles $(F \geq 658.3, p<0.01)$ with no difference between groups $(F \leq 1.380, p>0.05)$. Cases experienced more pain on testing on decline board $(E S=0.69, p<0.01)$. For symptomatic limbs pain $\left(r_{s}=0.458\right.$ $0.641, p \leq 0.05)$, but not VISA-P (Victoria Institute of Sport Assessment) ( $r_{s}=0.053$ $0.090, p>0.05)$, correlated with extensor knee moment.

Interpretation. Knee valgus alignment is a plausible risk factor for patellar tendinopathy. Conclusions relating to causation are limited by the cross-sectional study design. Increasing squat depth, use of a declined surface and isolating the 
eccentric phase enable progression of loading prescription guided by pain. Data is provided to assist in prescription of progressive loading programmes. Pain on activity is a useful guide to titrate load dosage.

\section{Introduction}

Patellar tendinopathy is a prevalent condition in physically active populations particularly those subjected to plyometric loads ${ }^{1}$. As mechanical loading is considered the primary driver through a progressive pathological model ${ }^{2}$ it is logical to look for ways to identify "excessive load" and modify this. Several studies using analysis of jumping describe loading associated with patellar tendinopathy ${ }^{3-7}$. In volleyball players increased forces in the knee extensor mechanism have been associated with patellar tendinopathy ${ }^{34}$. Motion at other joints as shown in the ankle and trunk may contribute to excessive patella tendon forces ${ }^{5}$. Biomechanical differences may develop as a result of tendon pathology or represent aetiological factors. Limiting flexion at the knee during a jump has been seen in those with previous patellar tendinopathy ${ }^{6}$ and, in a multi-sport cohort, when fatigued ${ }^{7}$. These examples may indicate a protective mechanism.

Jumping is often too high a load for symptomatic patients to tolerate due to pain. Patients with chronic degenerative patellar tendinopathy often find jumping or hopping painful ${ }^{8}$. The single leg squat (SLS) is a routine test for basic biomechanical assessment in clinic and has relevance to jumping mechanics ${ }^{9}$. Parameters looked for on clinical examination include pelvic obliquity, anterior pelvic tilt, hip internal rotation, peak knee flexion angle, peak knee valgus abduction (valgus) angle and movement variability ${ }^{10}$. Such factors have been included in functional movement screens (FMS) with the aim of identifying those at increased risk of injury ${ }^{10-12}$. However, Bushman's study of 2476 soldiers screened showed low predictive value of FMS at 6 months follow up ${ }^{13}$. This highlights the need to re-examine the relationship 
between these factors and how they contribute to injury risk. Excessive anterior pelvic tilt with hip extension has been proposed to lead to greater knee flexion at footstrike increasing load of the knee extensor mechanism and potentially predisposing to patellar tendinopathy ${ }^{14}$. As anterior tilt is caused by weak external hip rotators and gluteal/abdominal muscles exercises to strengthen these muscles are commonplace. There is little evidence assessing kinematics and kinetics in patellar tendinopathy. The identification and quantification of parameters presenting with patellar tendinopathy will inform and enable health care professionals involved in exercise prescription. This has been proven to be effective in other conditions such as Patellofemoral Pain Syndrome (PFPS) ${ }^{15}$.

Squats are also effective in treating patellar tendinopathy ${ }^{1617}$ and can be modified as part of a progressive loading programme. Additional use of a decline board increases tendon forces ${ }^{18}$ and $\operatorname{strain}^{19}$. This study aims to assess kinematic and kinetic differences between patients with patellar tendinopathy and healthy controls when performing increasingly demanding variations of the SLS. It is hypothesised that cases with patellar tendinopathy will exhibit greater anterior pelvic tilt, pelvic obliquity, hip adduction, hip internal rotation, knee valgus and reduced knee flexion in comparison to both their asymptomatic side and a group of healthy controls.

\section{Methods}

A total of 24 controls and 25 cases were screened. Inclusion criteria for controls were males aged 18-55 and exclusion criteria musculoskeletal injury in the preceding 6 months or occupational restrictions concerning physical activity. For cases inclusion criteria, assessed by a Sport and Exercise Medicine Consultant (PB) and physiotherapist (JW), were patellar tendinopathy diagnosis of at least 6 months 
chronicity with minimal improvement following best practice management including eccentric loading, heavy slow resistance and extra-corporeal shockwave therapy aged 18-55, ultrasound evidence of chronic degenerative patellar tendinopathy including thickening, hypoechogenic changes and neovascularisation. All cases assessed experienced pain on attempting to run or jump and were independently certified as medically unfit for their full military role by an Armed Forces General Practitioner prior to referral. Exclusion criteria were females and patients with a concurrent alternate lower limb diagnosis. The Ministry of Defence Research Ethics Committee approved the study (684/MODREC/15) and all participants gave written informed consent. Participants undertook movements described below.

For the small knee bend (SKB) verbal instruction was given:

"Stand on one leg with your foot pointing forward. Place the unsupported foot behind you by bending your knee $90^{\circ}$. While keeping your body upright, keeping your pelvis and heel in position, bend your knee so that your knee is in line with your 2nd toe and moves past it until you can no longer see the tape line. "10

5 repetitions were tested ${ }^{20}$ allowing 2-3 practice repetitions immediately prior to testing $^{21} 22$. There was one minute of rest between trials ${ }^{22} 23$.

Squat movements were standardised and 2 further tests the SLS and with the addition of a $25^{\circ}$ decline board (see figure 1$)^{18}$ the single leg decline squat (SLDS) performed. Participants were instructed for SLS and SLDS to squat to $60^{\circ}$ knee flexion using metronome pacing over a 4 second cycle 2224 . The non-stance leg was flexed at the knee to $90^{\circ 22}$. Again 5 repetitions were captured following 2-3 practice squats with a minute's rest between trials.

FIGURE 1 INSERTED HERE - Caption below

Figure 1 - Decline board with example of foot placement 
The testing sequence was SKB followed by SLS then SLDS. Tests were conducted bilaterally with the first leg to be tested decided by coin toss in controls and asymptomatic limb tested prior to the symptomatic limb in cases. Leg dominance according to which leg a participant would kick a ball with was recorded. Pain caused by the squats after each trial was monitored with a $100 \mathrm{~mm}$ visual analogue scale.

For kinematic and kinetic data acquisition and processing 8 body segments (feet, shank, thigh, pelvis and trunk) were defined using retro-reflective markers placed on anatomical landmarks by the same operator $(\mathrm{RBD})$ as previously described by this laboratory ${ }^{25}$ (article submitted, Barker-Davies 2017). Joint moments were normalised to participant mass.

A VICON (Oxford, UK) 10-camera motion capture system and one AMTI (Boston, USA) force plate captured data at $120 \mathrm{~Hz}$ and $1200 \mathrm{~Hz}$ respectively. Following static and range of motion calibration trials participants performed the squats as described above.

All squat trials were trimmed to the corresponding $2^{\text {nd }}, 3^{\text {rd }}$ and $4^{\text {th }}$ repetitions. Data was labelled in Vicon Nexus (version 2.1) and processed in Visual 3D (C-motion version 6.0, Rochelle, USA). Kinematic data was filtered using a $6 \mathrm{~Hz}$ low pass bidirectional Butterworth filter ${ }^{26}$ and gaps were interpolated using a 3rd order least squares fit (maximum 10 frames) $)^{27}$. Kinetic data was filtered separately at $50 \mathrm{~Hz}^{28}$.

Kinematics for variables based on previous research ${ }^{25}$ (article submitted, BarkerDavies 2017): hip adduction, knee flexion, pelvic tilt, pelvic obliquity and trunk flexion occurring at the time of peak knee flexion upon each of the three analysed squats were averaged. MANOVA tests were conducted for each of the three squat variations with subsequent ANOVA and bonferroni corrected post-hoc comparisons where 
applicable. Using G-Power ${ }^{29}$ a medium effect size $\left(f^{2}(V)\right.$ 0.25) combined with a-level (0.05) and $80 \%$ power required a total sample of 39 participants for a MANOVA global effect tests for 5 kinematic variables and 3 groups: controls, symptomatic and asymptomatic limbs of cases.

For curve analysis kinematic and kinetic data from the trunk, pelvis, hip and knee were normalised to $100 \%$ of the squat cycle between the points of minimum knee flexion. Means were plotted in pairwise comparisons between groups with bootstrapped t-tests and $95 \%$ confidence intervals to identify phases of the squat cycle where significant differences occurred.

Extensor knee moment was extracted at $30^{\circ}, 45^{\circ}$ and $60^{\circ}$ during both concentric and eccentric phases. Force can be calculated from moment data if the length of the lever (moment arm) from where the centre of rotation occurs to where the force is applied is known. In this case this is the distance from knee joint centre to intersect the patella tendon. Smidt's ${ }^{30}$ calculations provide an estimation of moment arm length which varies through knee flexion range. By dividing extensor knee moment by patella tendon moment arm as demonstrated by Frohm ${ }^{31}$ patella tendon force was calculated at $30^{\circ}, 45^{\circ}$ and $60^{\circ}$. Those values represent instantaneous data so to get an appreciation of mechanical loading throughout the squat cycle moment impulse was calculated. For paced squats extensor knee moment was integrated to calculate impulse (area under the curve) from minimum knee flexion angle to peak for the eccentric phase and peak to minimum for the concentric phase. Calculations were undertaken using SPSS ( $v$ 23, IBM, Armonk, NY, USA), Microsoft Excel (v 14.7.6, Microsoft, California, USA) and Matlab (v2014a, Mathworks, USA).

\section{Results}


Twenty-one cases and 22 healthy controls participated in the study. In addition 2 control participants did not meet exclusion criteria having on-going lower limb injuries and were not enrolled. 2 further healthy controls were screened and excluded having sustained lower limb injuries between invitation to participate and laboratory assessment ( 1 hamstring strain and 1 ankle sprain). A further 4 cases were screened and excluded: 2 cases declined consent, due to availability and 2 cases had concurrent intra-articular knee pathology. There were no significant demographic differences between groups (table 1). Cases had a median symptom duration of 18 months (range 10-120), median VISA-P of 45 (range 19-70), median neovascularity grade (Modified Ohberg Score ${ }^{32}$ ) of 3.5 (range 2-4) and maximum tendon thickness of $7.9 \mathrm{~mm}(\mathrm{SD}=1.7)$. Asymptomatic limbs of cases had a maximum tendon thickness of $4.7 \mathrm{~mm}(\mathrm{SD}=1.9)$ and median neovascularity grade of 0 (range $0-4)$. The SKB, SLS and SLDS were completed by 20,19 and 16 cases respectively as limited by pain. All controls completed the protocol without pain.

\section{TABLE 1 - INSERT HERE}

\subsection{Kinematic and kinetic differences relevant to clinical examination}

Gases squatted to significantly less depth than controls by $6.62^{\circ}(95 \%$ Cl $0.66-12.59$, $p<0.05$ ) when performing the SLS (appendix 1) there were no other significant differences in a priori powered kinematics at peak knee flexion (table 2). On their symptomatic side cases squatted to significantly less depth than healthy controls by $6.62^{\circ}(95 \% \mathrm{Cl} 0.66-12.59, \mathrm{p}<0.05)$ when performing the SLS (appendix 1). There were no other significant differences in hip adduction, knee flexion, pelvic obliquity, pelvic tilt or trunk flexion angles extracted at peak knee flexion between symptomatic limbs, asymptomatic limbs or healthy controls. 
Exploratory curve analysis revealed the majority of significant differences were between injured symptomatic limbs and healthy controls (figure 2). There is greater abduction (valgus) positioning of the knee in cases symptomatic limbs with decreased abduction (valgus) moment compared to healthy controls throughout the movement. Symptomatic limbs Gases initiate and complete squatting with more trunk, hip and knee flexion which is associated with increased hip/knee extensor moment and hip/knee internal rotation moment at initiation and completion of the squat compared to healthy controls. There was only one instance of significant difference in curve analysis between symptomatic and asymptomatic limbs with symptomatic limbs exhibiting greater knee abduction angle between 10 and $14 \%$ of the squat cycle. All significant differences are summarised in table 3.

\section{FIGURE 2 - INSERT HERE - Caption below:}

Figure 2. Summary of kinematic and kinetic differences between symptomatic limbs of cases (blue) and healthy controls (red). Shaded areas represent bootstrapped $95 \%$ confidence intervals. The bar along the $x$-axis indicates time-points where significant difference occurred. There is greater abduction (valgus) positioning of the knee in cases (g) with decreased abduction (valgus) moment (h) compared to healthy controls throughout the movement. Symptomatic limbs initiate and complete squatting with more trunk (i), hip (a) and knee (d) flexion which is associated with increased hip (b)/ knee (e) extensor moment and hip (c)/ knee (f) internal rotation moment at initiation and completion of the squat.

\section{TABLE 3 - INSERT HERE}

\subsection{Extensor knee moments and patella tendon force production relevant for exercise prescription}

Further examination of knee moment and force production was analysed on the SLS and SLDS only as they are more standardised and more commonly used for exercise 
prescription than the SKB. Extensor knee moments (table 4) extracted during the eccentric phase were generally slightly higher than the concentric phase (range ES 0.15-0.42 where $\mathrm{p}<0.05$ on SLS at $30^{\circ}$ knee flexion within asymptomatic limbs and controls, all groups at $45^{\circ}$ knee flexion and on SLDS within controls at $45^{\circ}$ and $60^{\circ}$ knee flexion (appendix 2)). Use of a decline board increased extensor knee moments and resulting patella tendon force by $9-18 \%$ compared to a flat surface (range ES 0.62-1.45, $\mathrm{p} \leq 0.01$ (appendix 3)). There was a trend for lower extensor knee moments at all angles in the healthy control group compared to symptomatic and asymptomatic limbs but this was only significant at $30^{\circ}$ knee flexion $\left(x^{2}=7.704\right.$, $\mathrm{p}<0.05)$ with asymptomatic limbs exhibiting greater extensor knee moment than healthy controls (mean ranks $25.85 \vee 39.74, p<0.05$, ES=0.39). Two-way mixed ANOVAs (group $v 30^{\circ} / 45^{\circ} / 60^{\circ}$ knee flexion) confirmed significant main effects on SLS and SLDS for greater extensor knee moment at increased knee flexion angle $(F \geq 658.3, p<0.01)$ but not group $(F \leq 1.380, p>0.05)$ with no interaction between group and knee flexion angle $(F \leq 0.598, p>0.05)$ (appendix 4).

\section{TABLE 4 - INSERT HERE}

Extensor knee moment impulse (table 4) was 30-43\% greater during the eccentric phase than concentric phase of all squats with a larger effect size for symptomatic and asymptomatic limbs of cases (range ES 1.16-1.32, $\mathrm{p}<0.01$ ) compared to healthy controls (range ES 0.52-61). Despite this there was no interaction between group and phase $\left(F_{(2,60)}=1.478, p>0.05\right)($ appendix 5$)$. In all groups eccentric, concentric and combined total extensor knee moment impulses were $36-51 \%$ greater (range ES 1.19-1.68, $p<0.01$ )(appendix 6) with the addition of the decline board. There were no differences between the groups in extensor knee moment impulses either on SLS or SLDS ( $F \leq 1.615, p>0.05$ )(appendix 7). Participants-Cases found squatting on their symptomatic side more painful with the addition of the decline board (median $57 \mathrm{v}$ 
$43.5 p<0.01, E S=0.69)$. Correlation was not significant between pain on squatting and impulse (SLS r=0.264, $p>0.05$ and $S L D S r_{s}=0.458, p>0.05$ ). Correlation between pain on squatting and extensor knee moments was significant at $30^{\circ}$ and $45^{\circ}$ on SLS $(r=0.458, p<0.05$ and $r=0.535, p<0.05$ respectively $)$ and at $60^{\circ}$ on SLDS $\left(r_{s}=0.641\right.$, $\mathrm{p}<0.05)$. VISA scores did not predict impulse generated on performing either squat $\left(S L S r_{s}=0.090\right.$ and SLDS $r_{s}=0.053, p>0.05$ )(appendix 8).

\section{Discussion}

The main finding of this study is that cases with patellar tendinopathy on their symptomatic side only exhibit greater knee valgus on squatting compared to healthy controls.

Particular attention should be paid to examining the initial single leg stance posture as the majority of patients should be able to achieve this and several other significant differences were demonstrated at the start/finish of the squat cycle. These include increased trunk, hip and knee flexion associated with increased knee internal rotation moment and extensor knee moment in cases. Greater extensor knee moment at the start/finish of the squat cycle may be indicative of excessive patella tendon loading whilst the lack of differences at greater squat depth can be explained by the requirement in this model to move to a standardised position. Chronically increased extensor knee moment at minimal knee flexion angles typical for single leg stance and ambulation may represent a plausible risk factor for tendinopathy in this heterogenous population. Clinically some of these patients with degenerative pathology are of a level of symptomology that requires a reduction in step count before loading programmes can progress. Reduced knee abduction (valgus) and hip flexion moments in cases may represent failed attempts to resist valgus collapse. This alignment pattern has been shown to be induced by neuromuscular fatigue 
which is another risk factor for musculoskeletal injury ${ }^{36}$. Excessive knee valgus angle has been associated in similar SLS models with lumbar stress injury ${ }^{33}$ and PFPS ${ }^{34}$. In patellar tendinopathy reduced arch height in standing, which would likely occur with valgus alignment, has been demonstrated in a cross sectional study compared to controls ${ }^{35}$. Conclusions relating to causation are limited by the cross-sectional nature of this study and further longitudinal research is planned.

The variations of squats in this study relate to practical and simple tests for clinical use. This study sought to standardise the depth and rate of squats so that peak patella tendon force was repeatable rather than an outcome measure in itself. Having achieved this its aim was to elucidate movement faults commonly looked for and identifiable without the use of specialist equipment. Had depth and rate not been standardised, as demonstrated by cases not quite managing to squat to the target of $60^{\circ}$, controls would likely have squatted much deeper than cases increasing the likelihood of false positive movement faults. This study is indicative of the low sensitivity of using solely peak kinematics as descriptors for such tests and has used curve analysis of the entire squat cycle to elucidate potentially important modifiable risk factors for pathology and targets for remedial physical therapy. What is considered abnormal by an experienced clinician can be difficult to quantify ${ }^{25}$ (article submitted, Barker-Davies 2017) but may include several other parameters such as movement excursions, variability and changes in acceleration. Differences were almost exclusively seen between symptomatic limbs and healthy controls. The common practice of using the asymptomatic limb as a comparator is not supported by the results of this study as almost no differences were seen between sides of cases. This may be due to motor deficits occurring prior to development of pathology or cross-education from the symptomatic to the asymptomatic limb ${ }^{37}$.

\subsection{Using single leg squats to prescribe patella tendon loading}


Modification of SLS to increase patella tendon loading as demonstrated here can be achieved by focusing on the eccentric phase, increasing the knee flexion angle and the addition of a decline board. Pain on squatting correlated with instantaneous moments, but not impulse, explaining more variance at angles where extensor knee moment is higher. This suggests pain is more an indicator of peak force rather than total dosage throughout movement. Pain may be related to force transmitted through the tendon above a threshold. Exercise into pain is a key feature of tendinopathy rehabilitation programmes proven to be effective ${ }^{38}$. Mechanisms have been proposed for this including inducing tendon strain. In the Achilles high as opposed to low tendon strain exercise has been shown to induce superior mechanical adaptation in the form of increased stiffness ${ }^{40}$. Pain on SLDS has been shown to correlate with reduced strain in patellar tendinopathy ${ }^{41}$. It may be that exercise into pain, which induces strain, is necessary to stimulate a healing response. This needs to be achieved without overloading the tendon ${ }^{42}$. VISA score did not correlate with extensor knee moments indicating it has limited structural validity relevant to loading prescription. This supports the notion that Loading dosage should be tailored to the individual within a pain monitoring framework ${ }^{43}$.

\section{INSERT TABLE 5 HERE}

This data can be used to prescribe progressive loading as follows (table 5). During an isometric hold for example patella tendon force at $60^{\circ}$ will be roughly twice that at $30^{\circ}$ and $10-20 \%$ higher with the addition of a decline board. For an isotonic movement if patients cannot tolerate the concentric phase, for example due to fatigue, $30-43 \%$ more extensor knee moment can be generated focussing on the eccentric phase. For the full isotonic movement progression to a decline board will increase load by $36-51 \%$. The additional loading a decline board provides is enhanced on isotonic movement compared to isometrics not only because the knee 
joint centre is moved further away from the centre of mass ${ }^{18}$ but in practice greater squat depth is achieved even when instructed to reach a specific target. Low frequency exercise (3 second pacing) has been shown to induce superior mechanical adaptions than high frequency exercise (1 second pacing) with matched tendon strain $^{40}$. Progression from isometric to isotonic then heavier loading phases (eccentric loading or heavy slow resistance) prior to the introduction of plyometrics is a pragmatic approach which allows for patient feedback on pain response.

\subsection{Limitations}

Patella tendon moment arms should be subject specific but as no regression equations have been made based on readily measurable anthropometrics ${ }^{44}$ it is reasonable to seek a match in terms of the whole study population. Smidt's participants $^{30}$ are similar to the military population in age, height and weight and therefore this technique to derive patella tendon force was used. Some cases were unable to complete the full protocol and on failing to squat to the full depth stipulated sample size was reduced for the more demanding tests and may have selected those with less severe pathology. This was mitigated by the test order starting with the least demanding task to maximise data capture.

Finally the nature of the pain experienced by cases is this controlled laboratory setting is likely to differ to that encountered in the real world. Cases often described pain being triggered by more plyometric activity such as jumping which generates increased extensor knee moment compared to walking, stair climbing and kicking and at a faster rate ${ }^{3}$. It was decided not to include a jumping test in this study due to the anticipated drop out rate as was seen with the more demanding decline squat. Further, causing a flare in symptoms in a cohort undergoing clinical treatment would have been undesirable. The use of controlled pacing and range of motion in 
squatting was designed to limit the chance of adverse effects, of which there were none.

\section{Conclusion}

Knee valgus alignment is a plausible risk factor for patellar tendinopathy. Conclusions relating to causation are limited by the cross-sectional study design. Increasing squat depth, use of a declined surface and isolating the eccentric phase enable progression of loading prescription guided by pain.

\section{Highlights}

- Patellar tendinopathy cases exhibit excessive valgus collapse on single leg squat

- Peak patella tendon force on single leg squat is similar in cases and controls

- Pain on activity correlates with tendon force and can be used to titrate loading

- Forces can be increased by eccentric phase loading and addition of a decline board

\section{Conflict of Interest Statement}

All authors declare no conflicts of interest.

\section{Acknowledgements}

This study has been funded by a Higher Education Funding Council for England (HEFCE) award to Loughborough University. There has been no involvement of 
funding organisations in data collection, analysis, interpretation or approval pertaining

to this manuscript.

\section{References}

1. Zwerver J, Bredeweg SW, van den Akker-Scheek I. Prevalence of Jumper's knee among nonelite athletes from different sports: a cross-sectional survey. The American journal of sports medicine 2011;39(9):1984-8. doi: $10.1177 / 0363546511413370$

2. Cook JL, Purdam CR. Is tendon pathology a continuum? A pathology model to explain the clinical presentation of load-induced tendinopathy. British journal of sports medicine 2009;43(6):409-16. doi: 10.1136/bjsm.2008.051193

3. Richards DP, Ajemian SV, Wiley JP, et al. Knee joint dynamics predict patellar tendinitis in elite volleyball players. The American journal of sports medicine 1996;24(5):676-83.

4. Bisseling RW, Hof AL, Bredeweg SW, et al. Are the take-off and landing phase dynamics of the volleyball spike jump related to patellar tendinopathy? British journal of sports medicine 2008;42(6):483-9. doi: 10.1136/bjsm.2007.044057

5. Janssen I, Steele JR, Munro BJ, et al. Predicting the patellar tendon force generated when landing from a jump. Medicine and science in sports and exercise 2013;45(5):927-34. doi: 10.1249/MSS.0b013e31827f0314

6. Bisseling RW, Hof AL, Bredeweg SW, et al. Relationship between landing strategy and patellar tendinopathy in volleyball. British journal of sports medicine 2007;41(7):e8. doi: 10.1136/bjsm.2006.032565

7. Edwards S, Steele JR, Purdam CR, et al. Alterations to landing technique and patellar tendon loading in response to fatigue. Medicine and science in sports and exercise 2014;46(2):330-40. doi: 10.1249/MSS.0b013e3182a42e8e

8. Visentini PJ, Khan KM, Cook JL, et al. The VISA score: an index of severity of symptoms in patients with jumper's knee (patellar tendinosis). Victorian Institute of Sport Tendon Study Group. Journal of science and medicine in sport/Sports Medicine Australia 1998;1(1):22-8.

9. Whatman C, Hume P, Hing W. Kinematics during lower extremity functional screening tests in young athletes - are they reliable and valid? Physical therapy in sport : official journal of the Association of Chartered Physiotherapists in Sports Medicine 2013;14(2):87-93. doi: 10.1016/j.ptsp.2012.06.001

10. Nadine Botha MW, Mo Gimpel, Sarah Mottram, Mark Comerford, Maria Stokes. Movement Patterns during a Small Knee Bend Test in Academy Footballers with Femoroacetabular Impingement (FAI). Working Papers in the Health Sciences, University of Southampton 2014;1:10 
11. Cook G, Burton L, Hoogenboom B. Pre-participation screening: the use of fundamental movements as an assessment of function - part 1. $\mathrm{N} \mathrm{Am} \mathrm{J}$ Sports Phys Ther 2006;1(2):62-72.

12. Cook G, Burton L, Hoogenboom B. Pre-participation screening: the use of fundamental movements as an assessment of function - part 2. $\mathrm{NAm} \mathrm{J}$ Sports Phys Ther 2006;1(3):132-9.

13. Bushman TT, Grier TL, Canham-Chervak M, et al. The Functional Movement Screen and Injury Risk: Association and Predictive Value in Active Men. The American journal of sports medicine 2016;44(2):297-304. doi: $10.1177 / 0363546515614815$

14. Brukner PK, K. Biomechanics of Common Sporting Injuries. In: Brukner P, ed. Clinical Sports Medicine. Australia: McGraw-Hill 2007:40-61.

15. Ferber R, Kendall KD, Farr L. Changes in knee biomechanics after a hipabductor strengthening protocol for runners with patellofemoral pain syndrome. Journal of athletic training 2011;46(2):142-9. doi: 10.4085/1062-6050-46.2.142

16. Purdam CR, Jonsson $\mathrm{P}$, Alfredson $\mathrm{H}$, et al. A pilot study of the eccentric decline squat in the management of painful chronic patellar tendinopathy. British journal of sports medicine 2004;38(4):395-7. doi: 10.1136/bjsm.2003.000053

17. Young MA, Cook JL, Purdam CR, et al. Eccentric decline squat protocol offers superior results at 12 months compared with traditional eccentric protocol for patellar tendinopathy in volleyball players. British journal of sports medicine 2005;39(2):102-5. doi: 10.1136/bjsm.2003.010587

18. Zwerver J, Bredeweg SW, Hof AL. Biomechanical analysis of the single-leg decline squat. British journal of sports medicine 2007;41(4):264-8; discussion 68. doi: 10.1136/bjsm.2006.032482

19. Kongsgaard M, Aagaard P, Roikjaer S, et al. Decline eccentric squats increases patellar tendon loading compared to standard eccentric squats. Clinical biomechanics 2006;21(7):748-54. doi: 10.1016/j.clinbiomech.2006.03.004

20. Wyndow N, De Jong A, Rial K, et al. The relationship of foot and ankle mobility to the frontal plane projection angle in asymptomatic adults. Journal of foot and ankle research 2016;9:3. doi: 10.1186/s13047-016-0134-9

21. Song CY, Huang HY, Chen SC, et al. Effects of femoral rotational taping on pain, lower extremity kinematics, and muscle activation in female patients with patellofemoral pain. Journal of science and medicine in sport / Sports Medicine Australia 2015;18(4):388-93. doi: 10.1016/j.jsams.2014.07.009

22. Scattone Silva R, Serrao FV. Sex differences in trunk, pelvis, hip and knee kinematics and eccentric hip torque in adolescents. Clinical biomechanics 2014;29(9):1063-9. doi: 10.1016/j.clinbiomech.2014.08.004

23. Nakagawa TH, Maciel CD, Serrao FV. Trunk biomechanics and its association with hip and knee kinematics in patients with and without patellofemoral pain. Man Ther 2015;20(1):189-93. doi: 10.1016/j.math.2014.08.013

24. Stickler L, Finley M, Gulgin H. Relationship between hip and core strength and frontal plane alignment during a single leg squat. Physical therapy in sport : official journal of the Association of Chartered Physiotherapists in Sports Medicine 2015;16(1):66-71. doi: 10.1016/j.ptsp.2014.05.002 
25. Barker-Davies RM, Roberts A, Bennett AN, et al. Single leg squat ratings by clinicians are reliable and predict excessive hip internal rotation moment. Gait \& posture 2018;61:453-58. doi: 10.1016/j.gaitpost.2018.02.016

26. Winter DA, Sidwall HG, Hobson DA. Measurement and reduction of noise in kinematics of locomotion. Journal of biomechanics 1974;7(2):157-9.

27. Howarth SJ, Callaghan JP. Quantitative assessment of the accuracy for three interpolation techniques in kinematic analysis of human movement. Comput Methods Biomech Biomed Engin 2010;13(6):847-55. doi: 10.1080/10255841003664701

28. Roewer BD, Ford KR, Myer GD, et al. The 'impact' of force filtering cut-off frequency on the peak knee abduction moment during landing: artefact or 'artifiction'? British journal of sports medicine 2014;48(6):464-8. doi: 10.1136/bjsports-2012-091398

29. Faul F, Erdfelder E, Lang AG, et al. G*Power 3: a flexible statistical power analysis program for the social, behavioral, and biomedical sciences. Behavior research methods 2007;39(2):175-91.

30. Smidt GL. Biomechanical analysis of knee flexion and extension. Journal of biomechanics 1973;6(1):79-92.

31. Frohm A, Halvorsen K, Thorstensson A. Patellar tendon load in different types of eccentric squats. Clinical biomechanics 2007;22(6):704-11. doi: 10.1016/j.clinbiomech.2006.12.006

32. Watson J B-DR, Bennett, A, Fong D, Wheeler P, Lewis M, Ranson C. Sport and Exercise Medicine consultants are reliable in assessing tendon neovascularity using ultrasound Doppler. BMJ Open Sport Exerc Med 2017

33. Bayne H, Elliott B, Campbell A, et al. Lumbar load in adolescent fast bowlers: A prospective injury study. Journal of science and medicine in sport / Sports Medicine Australia 2016;19(2):117-22. doi: 10.1016/j.jsams.2015.02.011

34. Nakagawa TH, Moriya ET, Maciel CD, et al. Trunk, pelvis, hip, and knee kinematics, hip strength, and gluteal muscle activation during a single-leg squat in males and females with and without patellofemoral pain syndrome. The Journal of orthopaedic and sports physical therapy 2012;42(6):491-501. doi: 10.2519/jospt.2012.3987

35. Crossley KM, Thancanamootoo K, Metcalf BR, et al. Clinical features of patellar tendinopathy and their implications for rehabilitation. Journal of orthopaedic research : official publication of the Orthopaedic Research Society 2007;25(9):1164-75. doi: 10.1002/jor.20415

36. Weeks BK, Carty CP, Horan SA. Effect of sex and fatigue on single leg squat kinematics in healthy young adults. BMC musculoskeletal disorders 2015;16:271. doi: 10.1186/s12891-015-0739-3

37. Heales LJ, Lim EC, Hodges PW, et al. Sensory and motor deficits exist on the non-injured side of patients with unilateral tendon pain and disability-implications for central nervous system involvement: a systematic review with meta-analysis. British journal of sports medicine 2014;48(19):1400-6. doi: 10.1136/bjsports-2013-092535

38. Silbernagel KG, Thomee R, Eriksson BI, et al. Continued sports activity, using a pain-monitoring model, during rehabilitation in patients with Achilles tendinopathy: a randomized controlled study. The American journal of sports medicine 2007;35(6):897-906. doi: 10.1177/0363546506298279 
39. Malliaras P, Barton CJ, Reeves ND, et al. Achilles and patellar tendinopathy loading programmes : a systematic review comparing clinical outcomes and identifying potential mechanisms for effectiveness. Sports medicine 2013;43(4):267-86. doi: 10.1007/s40279-013-0019-z

40. Arampatzis A, Peper A, Bierbaum S, et al. Plasticity of human Achilles tendon mechanical and morphological properties in response to cyclic strain. Journal of biomechanics 2010;43(16):3073-9. doi: 10.1016/j.jbiomech.2010.08.014

41. Lee WC, Zhang ZJ, Masci L, et al. Alterations in mechanical properties of the patellar tendon is associated with pain in athletes with patellar tendinopathy. Eur J Appl Physiol 2017;117(5):1039-45. doi: 10.1007/s00421-017-3593-1

42. Magnusson SP, Langberg $\mathrm{H}$, Kjaer M. The pathogenesis of tendinopathy: balancing the response to loading. Nat Rev Rheumatol 2010;6(5):262-8. doi: 10.1038/nrrheum.2010.43

43. Silbernagel KG, Crossley KM. A Proposed Return-to-Sport Program for Patients With Midportion Achilles Tendinopathy: Rationale and Implementation. The Journal of orthopaedic and sports physical therapy 2015;45(11):876-86. doi: 10.2519/jospt.2015.5885

44. Tsaopoulos DE, Baltzopoulos V, Maganaris CN. Human patellar tendon moment arm length: measurement considerations and clinical implications for joint loading assessment. Clinical biomechanics 2006;21(7):657-67. doi: 10.1016/j.clinbiomech.2006.02.009 
Table 1 Demograhics of participants

Controls $\mathrm{n}=\mathbf{2 2}$

Cases $\mathrm{n}=\mathbf{2 1}$

Difference

between

groups/sides

p value

\begin{tabular}{llll}
\hline Age, years, mean & $34.0(6.5)$ & $30.5(5.9)$ & 0.075
\end{tabular}

(SD)

\begin{tabular}{llll}
\hline $\begin{array}{l}\text { Height, m, mean } \\
(\mathrm{SD})\end{array}$ & $1.79(0.06)$ & $1.78(0.08)$ & 0.991 \\
\hline $\begin{array}{l}\text { Weight, Kg, mean } \\
(\mathrm{SD})\end{array}$ & $85.3(9.2)$ & $88.4(10.8)$ & 0.312 \\
\hline $\mathrm{BMI}, \mathrm{Kg} / \mathrm{m}^{2}(\mathrm{SD})$ & $26.8(2.72)$ & $27.7(3.2)$ & 0.306 \\
\hline
\end{tabular}

Pre-test VAS pain, $0(0)$

$25.9(15.3)$

0-100mm, mean

(SD)

VAS pain on SKB, $0(0)$

0-100mm, mean

(SD)

*Symptomatic side: $\quad$ * $<0.0005$

35.1 (22.3)

${ }^{*}$ Asymptomatic

side: 8.4 (14.3)

\begin{tabular}{|c|c|c|c|}
\hline $\begin{array}{l}\text { VAS pain on SLS, } \\
0-100 \mathrm{~mm} \text {, mean } \\
\text { (SD) }\end{array}$ & $0(0)$ & $\begin{array}{l}\text { *Symptomatic side: } \\
41.5(22.9) \\
{ }^{*} \text { Asymptomatic } \\
\text { side: } 7.1(13.1)\end{array}$ & ${ }^{*}<0.0005$ \\
\hline $\begin{array}{l}\text { VAS pain on } \\
\text { SLDS, } 0-100 \mathrm{~mm} \text {, } \\
\text { mean (SD) }\end{array}$ & $0(0)$ & $\begin{array}{l}{ }^{*} \text { Symptomatic side: } \\
43.8(26.5) \\
{ }^{*} \text { Asymptomatic } \\
\text { side: } 10.5(14.0)\end{array}$ & ${ }^{*}<0.0005$ \\
\hline Roles, frequency & $\begin{array}{l}\text { Aircraft } \\
\text { technician=4, } \\
\text { Administrative } \\
\text { Officer=5, Military } \\
\text { Nurse=6, } \\
\text { 5=Physical } \\
\text { Training } \\
\text { instructors, } \\
\text { 2=Doctors }\end{array}$ & $\begin{array}{l}\text { 3=Electric/engineer } \\
\text { technician, } \\
\text { 1= Seaman, } \\
2=\text { Driver, } 2= \\
\text { Mechanic, } \\
\text { 3=IT/Comms } \\
\text { engineer, } \\
\text { 5=Infantry, } \\
3=\text { Admin. Officers, } \\
\text { 1=Radar operator, } \\
\text { 1=Tank loader, }\end{array}$ & - \\
\hline Leg dominance & Right $=20$ Left $=2$ & Right=21 Left=1 & - \\
\hline Injured leg & $\because$ & Right $=12$ Left $=9$ & \\
\hline
\end{tabular}

$P$ values relate to independent t-test unless otherwise stated. *Value relates to comparison between symptomatic and asymptomatic sides with significant difference paired t-tests and all residuals normally distributed. BMI=Body Mass Index, VAS=Visual Analogue Scale, SKB=Small knee bend, SLS=Single leg squat, SLDS=Single leg decline squat. 
Table 2 Mean kinematic variables at peak knee flexion (SD) powered for a priori MANOVA.

\begin{tabular}{|c|c|c|c|c|c|}
\hline Variable & Group & $\begin{array}{l}\text { Small knee } \\
\text { bend }\left({ }^{\circ}\right)\end{array}$ & $\begin{array}{l}\text { Single leg } \\
\text { squat }\left({ }^{\circ}\right)^{*}\end{array}$ & $\begin{array}{l}\text { Single leg } \\
\text { decline } \\
\text { squat }\left({ }^{\circ}\right)\end{array}$ & $\begin{array}{l}\text { ANOVA } \\
\text { (Single variable } \\
\text { within group) }\end{array}$ \\
\hline $\begin{array}{l}\text { Hip } \\
\text { adduction }\end{array}$ & $\begin{array}{l}\text { Symp } \\
\text { Asymp } \\
\text { Control }\end{array}$ & $\begin{array}{l}{ }^{\mathrm{a}} 6.1(7.2) \\
4.8(5.8) \\
\mathrm{a} 7.4(5.3)\end{array}$ & $\begin{array}{l}\text { ab9.6 (7.5) } \\
8.6(6.8) \\
\text { ab13.9 (7.6) }\end{array}$ & $\begin{array}{l}\text { b5.4 (6.5) } \\
5.1(6.1) \\
\text { b9.8 (6.2) }\end{array}$ & $\begin{array}{l}p=0.002 \\
p=0.072 \\
p<0.0005\end{array}$ \\
\hline $\begin{array}{l}\text { Knee } \\
\text { flexion }\end{array}$ & $\begin{array}{l}\text { Symp } \\
\text { Asymp } \\
\text { Control }\end{array}$ & $\begin{array}{l}\text { ac } 49.9(6.7) \\
\text { ac49.5 (5.2) } \\
\text { ac50.2 (9.7) }\end{array}$ & $\begin{array}{l}{ }^{a *} 57.9(6.3) \\
{ }^{a b} 61.2(6.9) \\
{ }^{a b *} 64.6(8.3)\end{array}$ & $\begin{array}{l}{ }^{\mathrm{c}} 65.2(9.0) \\
{ }^{\mathrm{bc}} 66.4(10.4) \\
{ }^{\mathrm{bc}} 72.2(6.7)\end{array}$ & $\begin{array}{l}p<0.0005 \\
{ }^{+} p<0.0005 \\
+p<0.0005\end{array}$ \\
\hline $\begin{array}{l}\text { Pelvic } \\
\text { Obliquity }\end{array}$ & $\begin{array}{l}\text { Symp } \\
\text { Asymp } \\
\text { Control }\end{array}$ & $\begin{array}{l}1.0(5.2) \\
\text { c3.0 (5.5) } \\
\text { ac } 0.3(4.0)\end{array}$ & $\begin{array}{l}0.9(6.6) \\
1.9(6.1) \\
\text { a5.6(6.9) }\end{array}$ & $\begin{array}{l}1.1(4.8) \\
\text { c2.4 (6.0) } \\
\text { c5.6 (5.8) }\end{array}$ & $\begin{array}{l}p=0.028 \\
p=0.036 \\
p<0.0005\end{array}$ \\
\hline Pelvic tilt & $\begin{array}{l}\text { Symp } \\
\text { Asymp } \\
\text { Control }\end{array}$ & $\begin{array}{l}\mathrm{a} 14.8(9.8) \\
15.0(9.6) \\
\mathrm{ac} 12.8(7.7)\end{array}$ & $\begin{array}{l}\text { a19.7 (10.0) } \\
19.6(9.4) \\
\text { a24.1 (10.9) }\end{array}$ & $\begin{array}{l}19.7(10.2) \\
20.0(11.0) \\
\text { c22.5 (10.2) }\end{array}$ & $\begin{array}{l}{ }^{+} p=0.026 \\
p=0.030 \\
p<0.0005\end{array}$ \\
\hline $\begin{array}{l}\text { Trunk } \\
\text { flexion }\end{array}$ & $\begin{array}{l}\text { Symp } \\
\text { Asymp } \\
\text { Control }\end{array}$ & $\begin{array}{l}\mathrm{c} 8.5(4.8) \\
\text { ac8.4 (5.1) } \\
\text { ac5.8 (5.3) }\end{array}$ & $\begin{array}{l}\# 11.9(4.6) \\
a \# 14.4(6.9) \\
a \# 16.4(11.1)\end{array}$ & $\begin{array}{l}{ }^{c} 17.1(9.1) \\
c 16.3(7.5) \\
c 18.1(9.4)\end{array}$ & $\begin{array}{l}{ }^{\&} p=0.020 \\
p=0.003 \\
p<0.0005\end{array}$ \\
\hline $\begin{array}{l}\text { MANOVA } \\
\text { (All variables b }\end{array}$ & ) & $\begin{array}{l}F_{(10,98)}=0.78 \\
p=0.652\end{array}$ & $\begin{array}{l}F_{(4,52)}=2.63 \\
p=0.045\end{array}$ & $\begin{array}{l}F_{(10,90)}=1.34 \\
p=0.220\end{array}$ & \\
\hline
\end{tabular}

Symp=Symptomatic limb, Asymp=Asymptomatic limb. MANOVA: *Bonferroni corrected post-hoc significant difference between groups. \#Trunk flexion on single leg squats excluded from MANOVA due to heterogeneous variance. ANOVA: Bonferroni corrected post-hoc significant differences: between asmall knee bend and single leg squat, ${ }^{b}$ single leg squat and single leg decline squat and 'small knee bend and single leg decline squat. +Mauchly's test of sphericity positive Greenhouse-Geisser correction applied. \&Non-parametric Friedman test used with follow-up Wilcoxon matched pairs. 
Table 3 Timepoints in squat cycle of significant differences in kinematic/kinetic data

\begin{tabular}{|c|c|c|c|c|}
\hline Test & Movement & $\begin{array}{l}\text { Angle/ } \\
\text { moment }\end{array}$ & $\begin{array}{l}\% \text { of squat cycle } \\
\text { with sig. diff. }\end{array}$ & $\begin{array}{l}\text { Direction } \\
\text { effect }\end{array}$ \\
\hline \multicolumn{5}{|c|}{ Hip Joint } \\
\hline $\mathrm{SKB}^{* a}$ & Flexion & Angle & $1-27$ & Sympt>CON \\
\hline SLS & Flexion & Angle & $1-13$ & Sympt>CON \\
\hline SLDS & $\begin{array}{l}\text { Internal } \\
\text { rotation }\end{array}$ & Moment & $31-83$ & CON>Sympt \\
\hline $\mathrm{SKB}^{* \mathrm{c}}$ & $\begin{array}{l}\text { Internal } \\
\text { rotation }\end{array}$ & Moment & $1-22,97-98$ & Sympt>CON \\
\hline SLS & $\begin{array}{l}\text { Internal } \\
\text { rotation }\end{array}$ & Moment & $2,4-6$ & Sympt>CON \\
\hline SLS & $\begin{array}{l}\text { Internal } \\
\text { rotation }\end{array}$ & Moment & $38-44,47-57,59-62$ & CON>Sympt \\
\hline SLDS $^{* b}$ & Flexion & Moment & $\begin{array}{l}1-15,17,93-94,96- \\
101\end{array}$ & CON>Sympt \\
\hline SKB & Flexion & Moment & $2-37,86-101$ & CON>Sympt \\
\hline SLS & Flexion & Moment & $2-21,94-101$ & CON>Sympt \\
\hline \multicolumn{5}{|c|}{ Knee joint } \\
\hline SLDS & Abduction & Angle & $1-10$ & Sympt>CON \\
\hline SLS & Abduction & Angle & $1-20,33-87,89-101$ & Sympt>CON \\
\hline SKB $^{*} \mathrm{~g}$ & Abduction & Angle & $1-34,40-101$ & Sympt>CON \\
\hline SLDS & Flexion & Angle & $38-72$ & CON>Sympt \\
\hline $\mathrm{SKB}^{* d}$ & Flexion & Angle & $1-26,89-101$ & Sympt>CON \\
\hline SLS & Flexion & Angle & $1-10$ & Sympt>CON \\
\hline SLS & Flexion & Angle & $49-54$ & CON>Sympt \\
\hline SLDS $^{* h}$ & Abduction & Moment & $1-81,86-101$ & CON>Sympt \\
\hline SKB & Abduction & Moment & $1-101$ & CON>Sympt \\
\hline SLS & Abduction & Moment & $2-101$ & CON>Sympt \\
\hline SLDS & $\begin{array}{l}\text { Internal } \\
\text { rotation }\end{array}$ & Moment & $\begin{array}{l}1-17,24-25,30,84- \\
101\end{array}$ & Sympt>CON \\
\hline $\mathrm{SKB}^{* f}$ & $\begin{array}{l}\text { Internal } \\
\text { rotation }\end{array}$ & Moment & $1-26,91-101$ & Sympt>CON \\
\hline SLS & $\begin{array}{l}\text { Internal } \\
\text { rotation }\end{array}$ & Moment & $1-6,9-14,92-101$ & Sympt>CON \\
\hline $\mathrm{SKB}^{*} \mathrm{e}$ & Extensor & Moment & $1-25,89-98,101$ & Sympt>CON \\
\hline SLS* & Extensor & Moment & $6-8$ & Sympt>CON \\
\hline SLS & Abduction & Angle & $10-14$ & Sympt>Asympt \\
\hline \multicolumn{5}{|l|}{ Trunk } \\
\hline SLDS $^{* i}$ & Flexion & Angle & $1-16,96-101$ & Sympt>CON \\
\hline SLS & Flexion & Angle & $2-13$ & Sympt>CON \\
\hline
\end{tabular}

SKB=small knee bend, SLS=single leg squat, SLDS=single leg decline squat, Sympt=symptomatic limbs of cases, Asympt=asymptomatic limbs of cases, $\mathrm{CON}=$ control. ${ }^{* a-i}$ Represented in figure 2 with letter corresponding to graph. 
Table 4 Instantaneous extensor knee moments and moment impulse at varying degrees of squat depth and phase of the squat cycle

Instantaneous extensor knee moment and patella tendon force extracted during the eccentric phase of squat movement

\begin{tabular}{|c|c|c|c|c|c|c|c|c|c|}
\hline $\begin{array}{l}\text { Knee } \\
\text { flexion } \\
\text { angle } \\
\left({ }^{\circ}\right)\end{array}$ & $\begin{array}{l}\text { Extensor knee } \\
\text { moment (Nm/Kg) } \\
\text { (SD) }\end{array}$ & $\begin{array}{l}\text { Patella } \\
\text { tendon } \\
\text { force } \\
(\mathrm{N} / \mathrm{Kg})\end{array}$ & $\begin{array}{l}\text { ANOVA } \\
\text { between } \\
\text { groups (F) }\end{array}$ & $\begin{array}{l}\text { Pairwise } \\
\text { Differences } \\
\text { SLDS v SLS } \\
(\mathrm{Nm} / \mathrm{Kg})\end{array}$ & $\begin{array}{l}\text { Phase of } \\
\text { Squat }\end{array}$ & $\begin{array}{l}\text { Moment Impulse } \\
(\mathrm{Nm} . \mathrm{s} / \mathrm{Kg})(\mathrm{SD})\end{array}$ & $\begin{array}{l}\text { ANOVA } \\
\text { between } \\
\text { groups } \\
\text { (F) }\end{array}$ & $\begin{array}{l}\text { Pairwise } \\
\text { SLDS v SLS } \\
(\mathrm{Nm} . \mathrm{s} / \mathrm{Kg})\end{array}$ & $\begin{array}{l}\text { Pairwise } \\
\text { Eccentric v } \\
\text { Concentric } \\
(\mathrm{Nm} . \mathrm{s} / \mathrm{Kg})\end{array}$ \\
\hline \multicolumn{10}{|c|}{ Single leg squat (SLS) } \\
\hline 30 & $\begin{array}{l}\text { Symp } 0.75(0.12) \\
\text { Asymp } 0.78(0.12) \\
\text { Control } 0.67(0.10)\end{array}$ & $\begin{array}{l}15.31 \\
15.92 \\
13.67\end{array}$ & $\begin{array}{l}\# x^{2}=7.704 \\
p=0.021 \\
{ }^{\#} A s y m p>C o n \\
p=0.035 \\
E S=0.39\end{array}$ & - & $\begin{array}{l}\text { Eccentric } \\
\text { phase }\end{array}$ & $\begin{array}{l}\text { Symp } 2.00(0.41) \\
\text { Asymp } 1.96(0.35) \\
\text { Control } 1.78(0.58)\end{array}$ & $\begin{array}{l}1.615 \\
p=0.207\end{array}$ & - & $\begin{array}{l}{ }^{*} 0.60(43 \%) \\
{ }^{*} 0.50(34 \%) \\
{ }^{*} 0.42(31 \%)\end{array}$ \\
\hline 45 & $\begin{array}{l}\text { Symp1.15 }(0.16) \\
\text { Asymp } 1.16(0.15) \\
\text { Control } 1.05(0.14)\end{array}$ & $\begin{array}{l}23.47 \\
23.67 \\
21.43\end{array}$ & $2.981 \mathrm{p}=0.059$ & - & $\begin{array}{l}\text { Concentric } \\
\text { phase }\end{array}$ & $\begin{array}{l}\text { Symp } 1.40(0.28) \\
\text { Asymp } 1.46(0.27) \\
\text { Control } 1.36(0.37)\end{array}$ & $\begin{array}{l}0.942 \\
p=0.396\end{array}$ & - & - \\
\hline 60 & $\begin{array}{l}\text { Symp } 1.46(0.22) \\
\text { Asymp } 1.51(0.13) \\
\text { Control } 1.40(0.18)\end{array}$ & $\begin{array}{l}31.06 \\
32.13 \\
29.79 \\
\end{array}$ & $0.924 p=0.405$ & - & Full ROM & $\begin{array}{l}\text { Symp } 3.40(0.59) \\
\text { Asymp } 3.43(0.57) \\
\text { Control } 3.14(0.83)\end{array}$ & $\begin{array}{l}1.156 \\
p=0.322\end{array}$ & - & - \\
\hline \multicolumn{10}{|c|}{ Single leg decline squat (SLDS) } \\
\hline 30 & $\begin{array}{l}\text { Symp } 0.83(0.12) \\
\text { Asymp } 0.85(0.14) \\
\text { Control } 0.77(0.12)\end{array}$ & $\begin{array}{l}16.94 \\
17.35 \\
15.71 \\
\end{array}$ & $2.227 p=0.118$ & $\begin{array}{l}{ }^{*} 0.09(12 \%) \\
{ }^{*} 0.08(10 \%) \\
{ }^{*} 0.11(16 \%)\end{array}$ & $\begin{array}{l}\text { Eccentric } \\
\text { phase }\end{array}$ & $\begin{array}{l}\text { Symp } 2.71(0.41) \\
\text { Asymp } 2.80(0.41) \\
\text { Control } 2.67(0.48)\end{array}$ & $\begin{array}{l}0.421 \\
p=0.659\end{array}$ & $\begin{array}{l}{ }^{*} 0.71(36 \%) \\
{ }^{*} 0.84(43 \%) \\
{ }^{*} 0.89(50 \%)\end{array}$ & $\begin{array}{l}{ }^{*} 0.69(34 \%) \\
{ }^{*} 0.67(32 \%) \\
{ }^{*} 0.66(30 \%)\end{array}$ \\
\hline 45 & $\begin{array}{l}\text { Symp } 1.32(0.15) \\
\text { Asymp } 1.30(0.16) \\
\text { Control } 1.24(0.13)\end{array}$ & $\begin{array}{l}26.99 \\
26.53 \\
25.31\end{array}$ & $1.847 p=0.168$ & $\begin{array}{l}{ }^{*} 0.17(15 \%) \\
{ }^{*} 0.14(12 \%) \\
{ }^{*} 0.19(18 \%) \\
\end{array}$ & $\begin{array}{l}\text { Concentric } \\
\text { phase }\end{array}$ & $\begin{array}{l}\text { Symp } 2.02(0.37) \\
\text { Asymp } 2.13(0.36) \\
\text { Control } 2.05(0.40)\end{array}$ & $\begin{array}{l}\# x^{2}=0.666 \\
p=0.717\end{array}$ & $\begin{array}{l}{ }^{*} 0.62(44 \%) \\
{ }^{*} 0.67(46 \%) \\
{ }^{*} 0.69(51 \%) \\
\end{array}$ & - \\
\hline 60 & $\begin{array}{l}\text { Symp } 1.67(0.19) \\
\text { Asymp } 1.68(0.14) \\
\text { Control } 1.63(0.13)\end{array}$ & $\begin{array}{l}35.53 \\
35.74 \\
34.68\end{array}$ & $0.902 p=0.403$ & $\begin{array}{l}{ }^{*} 0.23(16 \%) \\
{ }^{*} 0.16(11 \%) \\
{ }^{*} 0.23(16 \%)\end{array}$ & Full ROM & $\begin{array}{l}\text { Symp } 4.73(0.67) \\
\text { Asymp } 4.93(0.69) \\
\text { Control } 4.72(0.60)\end{array}$ & $\begin{array}{l}0.544 \\
p=0.584\end{array}$ & $\begin{array}{l}{ }^{*} 1.33(39 \%) \\
{ }^{*} 1.50(44 \%) \\
{ }^{*} 1.58(51 \%)\end{array}$ & - \\
\hline
\end{tabular}

*Significant difference $\mathrm{p}<0.0005$ \#Parametric assumptions violated Kruskal-Wallis $\mathrm{H}$ and Bonferroni corrected Mann Whitney-U used. aResiduals not normally distributed Wilcoxon matched pairs used. Greater extensor knee moment and therefore patella tendon force is generated at deeper knee flexion angles and on using a decline board. Symp=Symptomatic limbs, Asymp=Asymptomatic limb. The eccentric phase of squatting results in greater impulse than the concentric phase with use of a decline board resulting in greater impulse. 
Table 5. Recommendations for Progressive Loading Rehabilitation for patellar tendinopathy

\begin{tabular}{|c|}
\hline $\begin{array}{c}\text { Suggested progressive loading exercises for the patellar tendon } \\
\text { Maximum pain on activity } \leq 3 / 10 \text { without flare-up in symptoms the following day }\end{array}$ \\
\hline e flexion isometric hold \\
\hline Progress to $60^{\circ}$ knee flexion isometric hold to double patella tendon force (PTF) \\
\hline $\begin{array}{c}\text { Do not progress knee flexion angles above } 60^{\circ} \text {. There is an exponential increase in } \\
\text { patellofemoral force }\end{array}$ \\
\hline Add decline board to isometric hold to increase PTF $10-20 \%$ further \\
\hline Introduce isotonic exercises \\
\hline $\begin{array}{c}\text { Progress to a decline board to increase moment impulse (extensor torque throughout } \\
\text { the whole movement) up to } 50 \%\end{array}$ \\
\hline Isolate the eccentric phase to increase moment impulse by a further $30 \%$ \\
\hline $\begin{array}{l}\text { Once able to tolerate isotonic exercise on decline board or isolating eccentric phase } \\
\text { progress to weighted squats prior to plyometric activities }\end{array}$ \\
\hline
\end{tabular}




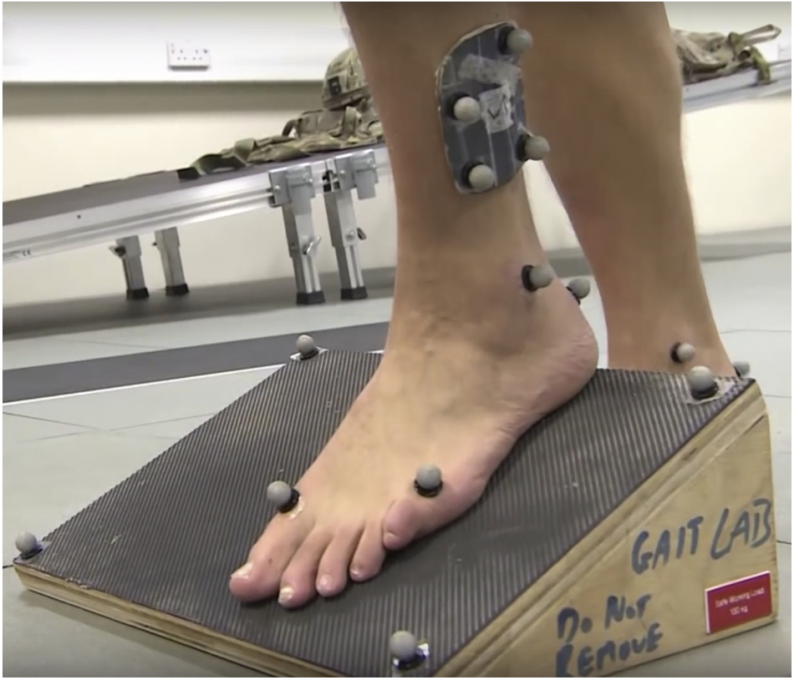

Figure 1 


\section{a. Hip flexion angle}

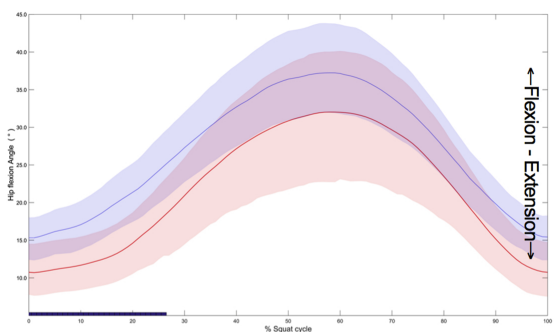

d. Knee flexion angle

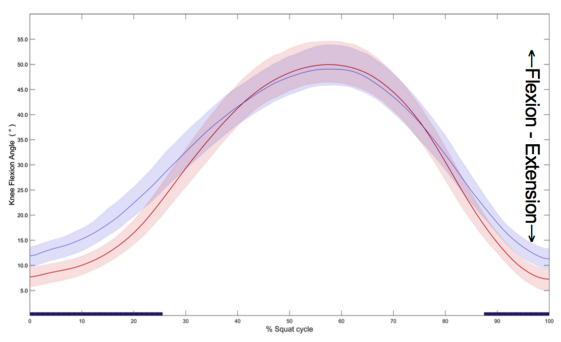

g. Knee adduction angle

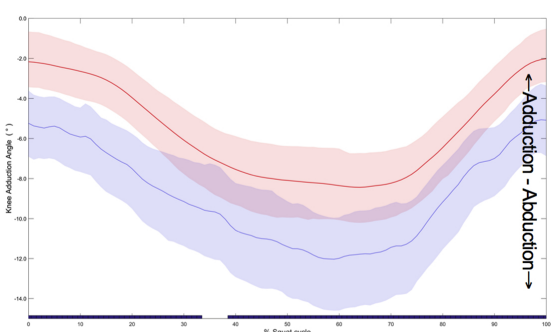

b. Hip flexion moment

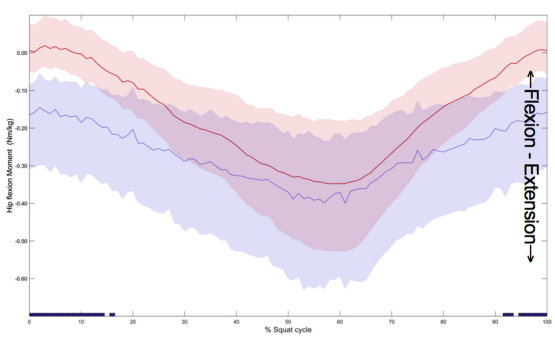

e. Knee flexion moment

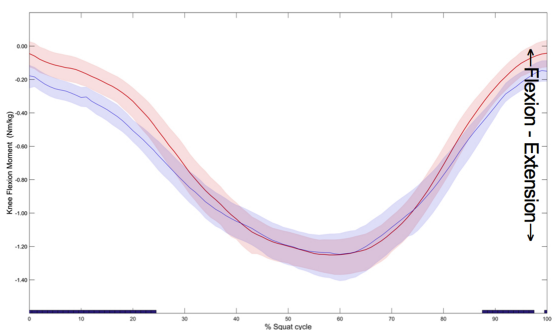

h. Knee adduction moment

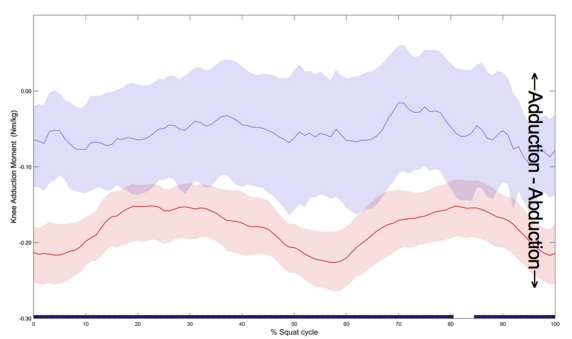

c. Hip internal rotation moment

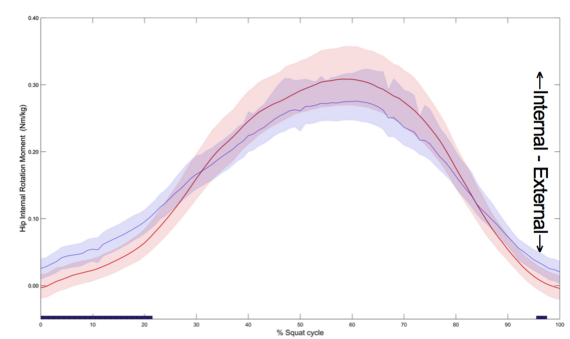

f. Knee internal rotation moment

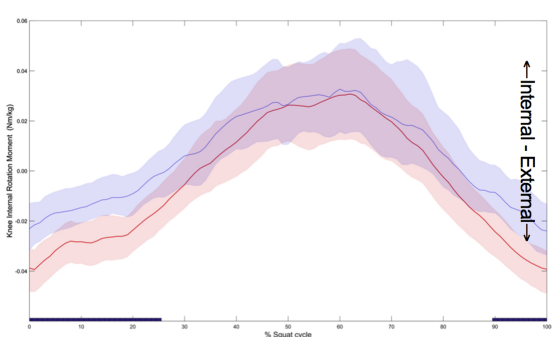

i. Trunk flexion angle

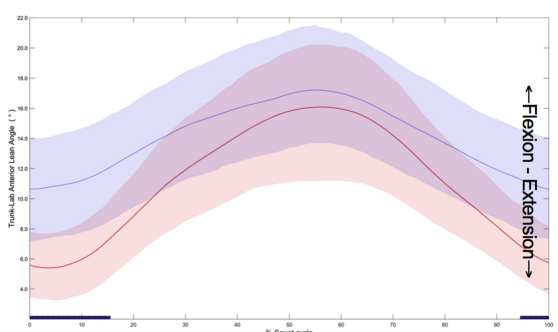

Figure 2 